subsequent loss of the eye. The young woman was badly impressed and in a short time developed a sort of fixed idea, that the child, which she was carrying, would have something wrong with its eyes. I heard afterwards from several persons, and from friends of the lady, confirmation of this part of her history : being pregnant, she often expressed apprehensions for the eyes of her future child. In due time she gave birth to a baby who " had no eyes." Under the eyelids, which could be opened well, only " flesh" was seen. There were no other deformities. The child died from an acute infection. The same apprehension haunted her during the whole of her second pregnancy, which ended in the birth of the present child. She has had no other children.

\title{
A FAMILY AFFECTED WITH KERATOCONUS AND ANTERIOR POLAR CATARACT
}

BY

P. Sander, M.D.

PORT SAID

IN 1927 , I had occasion to examine the eyes of a family consisting of the father, aged 70 years, and three unmarried daughters, aged 20,26 and 30 years. These people, of Maltese nationality, presented some features of physical and intellectual defectiveness. They were anaemic, of poor stature, with unhealthy grey skin of their faces carven with comedones and boils, saddle-shaped noses, badly developed teeth. They all showed different degrees of varying sequelae of long standing and neglected trachoma and its complications: shrinkage of the eyelids, entropion, vascularization and scars of the cornea, stenosis of ductus nasolacrymalis, etc. The two youngest had well pronounced symptoms of atrophic rhinitis, especially the youngest one-with formation of foul crusts. All of them were bearers of a curious combination of keratoconus and anterior polar cataract in each eye. They were all short sighted in different degrees-between - 5.0 D. sph. and - 20.0 D. sph., with low V. A., which could not be improved with glasses to an appreciable amount. In both younger girls keratoconus, although well pronounced, was not highly developed, no deep corneal opacities were present but polar cataract of small size-like a pin head. In all four eyes of these two girls there were a certain amount of dust-like opacities, scattered in all layers of the lenses seen in the Zeiss-Czapsky's microscope with slit-lamp illumination; but in one girl only there was more or less marked deposit of white matter, which could be considered as an 
" imprint" of the polar cataract. No myopic atrophy of the choroid round the optic discs. Myopia in one was - 5.0 D. sph. in each eye $;$ in the other between - 7.0 D. and - 9.0 D. sph. V. A. after correction was about $1 / 10$ in each eye in both patients.

The eldest sister presented the same condition, but much more developed, particularly in the R. E. The keratoconus was sharply prominent, corneae thinned, with rupture of Descemet's membrane and central opacity in both eyes. In the R. E. the cataract was in form of two cones of white material, situated close to each other in the central area of the pupil, each about $1 \mathrm{~mm}$. in diameter rising from the level of the anterior capsule, with one large and dense imprint. In the L. E. the cataract was single, about $2 \mathrm{~mm}$. in the base, protruding into the anterior chamber and with well pronounced imprint, with which it was connected by means of an opaque band. The dust-like opacities of bluishwhite colour were more numerous and somewhat more coarse grained than in the eyes of her sisters. Moderate staphyloma posticum and patches of choroido-retinal atrophy in the macular area in both eyes; V. A. of R. E. with $-18^{\circ} 0 \mathrm{D}$. sph. $=1 / 40$, L. E. with $-10 \cdot 0$ D. sph. $=1 / 20$. T. R. E. $=10 \mathrm{~mm} . \mathrm{Hg}$, and L. E. $=14 \mathrm{~mm}$. Hg. But the last figures should be taken cum grano salis as in all cases of pronounced keratoconus. The corneae are little resistant and liable to be distorted under the weight of the tonometer, and the central thin part of the cornea is easily impressed with the piston of the tonometer.

A very high degree of keratoconus with central corneal opacity was in the father's eyes. The polar cataracts of chalkwhite material were protruding into the anterior chamber, very pyramidal in form. The high degree of lenticular sclerosis- the very cataracta brunescens-did not allow of the examination of the deeper parts of the eyes. An upper iridectomy had been performed four years before my examination in both eyes. $\mathrm{He}$ could see with his glasses of $-20.0 \mathrm{D}$. sph. 1/100 in each eye.

There is one more sister in the same family who has also " weak eyes." They promised to come to see me again and to bring the other sister, but I never had another occasion to examine them. I should like to draw the attention of readers to the following facts. Anterior polar cataracts in combination with typical keratoconus was observed in each eye of four examined members of the same family, including two generations. The degree of development of the symptoms increases with the age of examined persons. All the members of the family present features of physical and mental degeneration. We used to think that anterior polar cataract is a sequel of the infection of the eyes during intra-uterine life, with perforation of the corneae and penetration by either microbes - probably gonococci, or their toxins to the lens. It seems that it 
would be stretching the imagination to apply this ingenious hypothesis to explain such an occurrence, as described above, and that it would be more natural to consider the polar cataract as one of the defects of development and nutrition, as with the other stigmata of degeneracy, for which no infection is considered necessary.

\title{
SYMPATHETIC OPHTHALMITIS DEVELOPED FORTY YEARS AFTER AN OPERATION ON THE FELLOW EYE
}

\author{
BY \\ P. Sander, M.D. \\ PORT SAID
}

J.C., Greek lady, aged 48 years, consulted me on June 22, 1928, for decrease of vision in her left eye, which she noticed two days previously, and which was increasing and was accompanied by pain in the same eye. The patient had suffered a great deal from eye troubles during her childhood. At the age of 8 years, that is to say, 40 years ago, her right eye was operated on in the French Hospital, in Alexandria. She could not tell what operation was done, or what had been the condition of the eye before the operation, but she remembered very well, that after the operation under general anaesthesia, there was severe pain in the affected eye for many weeks and she lost the sight permanently. During the whole of her life she had had sensations of heaviness and discomfort in this eye and tenderness to touch. In particular this eye had been tender during the last few months. The left eye was a source of long standing trouble in her youth. From time to time it became painful and red, and the sight failed. She consulted on many occasions many of the ophthalmic surgeons in Egypt, as well as abroad, but she was always told that it was trachomatous keratitis and was treated accordingly. They often advised excision of the right eye for aesthetic reasons, but she never agreed to it. During the last 15 years the left eye did not bother her.

Present State: R. E. Atrophic shrunken globe with gross corneal leucoma. The conjunctiva bulbi slightly injected and the eye very tender; a slight touch provoked a violent defensive retraction of the head. There was very pronounced enophthalmos with narrowing of the palpebral fissure. V. A. $=0 . \mathrm{L}$. E. Trachoma (Stage IV) Maculae corneae; ciliary injection. Corneal precipitates in form of delicate dew in the lower part of the cornea. The pupil narrow, of irregular form, did not react to light and could not be dilated with atropine drops. The fundus was not 